\title{
Editorial: \\ Preparing for a Nanotechnological Future
}

\author{
Akhlesh Lakhtakia \\ Editor-in-Chief
}

Nanotechnologies are socially transformative, especially in combination with information science and technology, biotechnology, and cognition sciences. With nanotech-enabled products estimated to constitute a multi-trillion-dollar market by 2015, we must prepare for a nanotechnological future.

Three years ago, I collaborated with two political scientists and a management communications expert to classify the technoscientific, social, political, legal, and ethical discourses on nanotechnology that had emerged by then [1]. At the heart of these discourses is the reality of political power and its exercise in the choices being made for society and their consequences. We found that most discourses were neither multidimensional, nor multidisciplinary, nor transparent. Faultlines existed between utopian and dystopian discourses, and there were many conflicting conceptions among nanotechnoscientists themselves.

Not much appears to have changed since then. Nanotechnoscientists almost invariably tend to glorify nanotechnology and exploit its caché. There is a generally enthusiastic business climate for nanotechnologies. Business leaders, due to their profit-oriented instincts, are focused on the products of incremental nanotechnologies. Bureaucracies in the industrialized and rapidly industrializing countries, perceiving the huge economic potential of nanotechnologies, are beginning to guide $\mathrm{R} \& \mathrm{D}$ and regulate industry.

In some countries, bureaucracies have even begun to incite academic debates on social, legal, and ethical implications of nanotechnological progress. Members of the fourth estate either glorify the world that they see nanotechnologies are creating or are alarmed by dystopian visions of a nanotechnological future. Some think tanks and social movements are becoming involved in evaluating the implications of nanotechnologies for the environment, health, human rights, and global justice. Social scientists are beginning to address social, economic, political, legal, religious, philosophical, and ethical implications of nanotechnologies. But the general public has yet to significantly grapple with or discuss nanotechnologies in any significant depth.

Planning for the future of any society is dictated by dominant viewpoints, which usually come from business, political, and religious leaders. Generally, technoscientists play minimal roles in shaping societal perspectives. In fact, they shirk from participation in societal debates.

The pace of technoscientific growth is so rapid that, as the Red Queen told Alice, one has to keep running just to stay at the same place. Technoscientists 
must no longer assume that social scientists, legislators, and other nontechnoscientists can deal satisfactorily with societal issues arising from that rapid pace. Instead, technoscientists must get involved in the societal issues arising from their scientific discoveries and technological achievements.

Ignorance about the various facets and implications of progress in nanotechnologies being widespread, programs of general education and information in today's industrial societies appear very desirable to prepare for a nanotechnological future. I believe that these programs must be actively created and guided by technoscientists.

\section{Reference}

[1] D. Munshi, P. Kurian, R. V. Bartlett, and A. Lakhtakia, "A map of the nanoworld: Sizing up the science, politics, and business of the infinitesimal," Futures 39, 432452 (2007) [doi: 10.1016/j.futures.2006.08.003]. 